\title{
Influence of surface shapes on the mechanical behaviour of friction welded wood bonds
}

\author{
Benjamin Hahn · Bernhard Stamm • \\ Yves Weinand
}

Received: 30 May 2014/Published online: 11 October 2014

(c) Springer-Verlag Berlin Heidelberg 2014

\begin{abstract}
Friction welding of wood is a fast and adhesivefree bonding technology for the production of timber joints with good mechanical characteristics making this type of connection interesting for applications in timber construction. However, the moisture stability is reduced due to swelling and shrinking deformations of the wood with changing climate conditions. These deformations lead to high internal stresses and thus irreversible crack formation within the bond. This paper describes experimental investigations carried out in order to improve the behaviour of welded interfaces under changing moisture contents by the use of interlocking surface shapes. Both, the influence of these modifications on the initial as well as on the residual joint strength was examined. The investigations revealed that the load bearing capacity of friction welded joints disappears completely if no additional measures, such as the geometrical modifications of the surface proposed herein, are taken. As a result the joint strength could be maintained even after a certain number of climate variations from very dry to very humid conditions. The described approach constitutes a practical solution to overcome the main drawback of the technology for industrial application.
\end{abstract}

\section{Introduction}

\subsection{Friction welding of wood}

The fabrication of laminar face-to-face joints between timber boards by means of friction welding is regarded as

B. Hahn $(\bowtie) \cdot$ B. Stamm · Y. Weinand

Laboratory for Timber Construction IBOIS, EPFL Lausanne, Lausanne, Switzerland

e-mail: Benjamin.Hahn@epfl.ch an interesting alternative to the application of currently used synthetic glues, mostly based on polyurethane or melamine adhesives. In the case of friction welding the bond is achieved by a combination of mechanically induced friction and pressure at the interface, generating thermal energy within a few seconds. As a result, the wood cell polymers are thermally decomposed into a viscous mixture of ligno-cellulosic monomers (Stamm et al. 2005). Once the friction movement stops, this viscous interfacial material hardens under the influence of a defined cooling pressure. Yet still applied on a research level, this adhesive-free bonding process results in a cohesive and stiff joint achieving load bearing capacities conceivable for timber construction applications under constant climate conditions. In theory, any wood species can be welded if the specific welding parameters, namely frequency $f$, amplitude $a$ and welding pressure $P_{\mathrm{w}}$, are adapted to the thermo-hygro-mechanic behaviour of the material. Two types of frictional movement can be distinguished, namely linear vibration welding (LVW) and circular vibration welding (ZVW). The idea to create wood bonds by means of the friction welding technology was first formulated by Sutthoff et al. (1996) and research was pursued subsequently at the IBOIS (Gliniorz and Natterer 2000) and other institutes (Gfeller et al. 2003; Pizzi et al. 2003). First investigations were carried out on small specimens of a few $\mathrm{cm}^{2}$ in size, but the acquirement of new welding devices, specially designed for research, made it possible to weld bigger surfaces of up to $500 \mathrm{~cm}^{2}$.

\subsection{Effects of upscaling}

Initial observations after welding of bigger samples showed that the size of the surface has two principal effects on the result. First, a significant influence on the thermal 
Fig. 1 Failure of friction welded samples with parallel (left) and perpendicular (right) grain orientation of the individual timber layers due to internal stresses as a result of changing moisture conditions
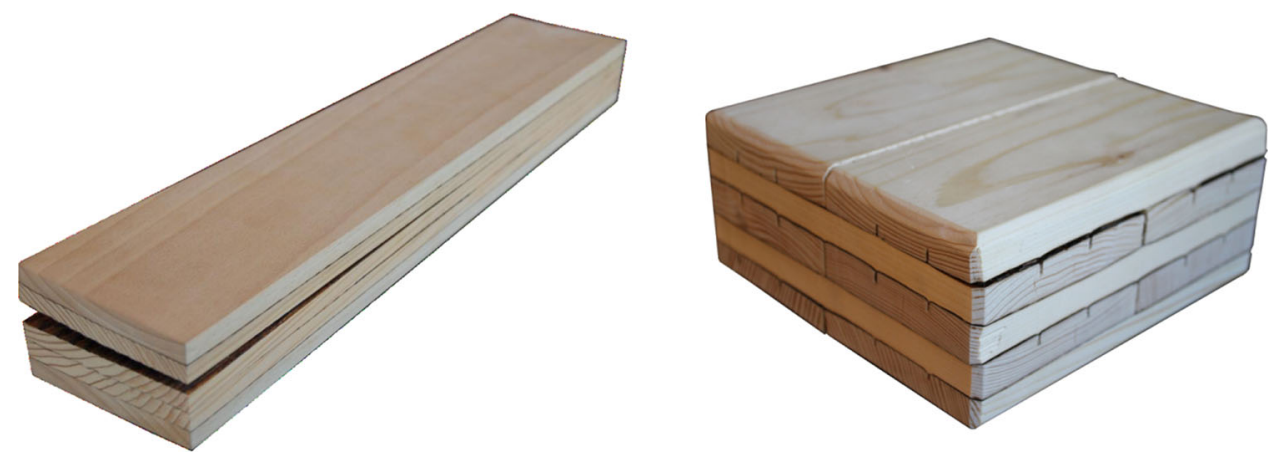

degradation process, and consequently on the final mechanical strength of the welded interface, has been observed. With increasing surface size strong local differences in welding quality arise. Concisely, within the interface edge region the welding process seems to run faster than inside the welded surface where large areas do not show sufficient thermal decomposition. The analysis of these scale effects is part of the ongoing research project and is described in Hahn et al. (2014a). Therein, technical measures, adapted to reduce these scale effects, have been deduced from the results of experimental investigations.

Second, deformations of the wood elements due to swelling and shrinking with changing climate conditions generate high internal stresses in the interface layer. These stresses, as a consequence, lead to crack formation and failure, as it is exemplarily shown in Fig. 1. Since these deformations occur mainly in the direction perpendicular to the grain, the critical internal stresses increase with increasing width of the welded elements, especially if they are welded with perpendicular fibre orientation. This fact restricts the potential application of the wood welding technology to ranges of relatively constant climatic conditions (interiors). Though, even for internal applications seasonal variations in moisture cannot completely be avoided. Solutions have to be found in order to assure the reliability of the joints.

\subsection{Objectives}

The investigations described herein were carried out for the purpose of improving the long-term stability of friction welded timber bonds. Double lap joints composed of timber layers with parallel fibre direction were produced using different groove-shaped geometries of the friction welded interface. Besides investigations into their mechanical resistance, it was examined if and to what extent the long-term resistance can be improved by interlocking of the grooves that are welded, similar to finger joints, one into another. In addition to an enlargement of the welding surface, keying of the elements and thus reduction of the deformations is expected. First attempts to improve the mechanical performance of the joint by grooved surfaces were done by Omrani et al. (2009). However, the size of the samples remained relatively small and no significant improvement of the mechanical behaviour has been observed. Furthermore, no investigations on the moisture stability of the bond have been carried out in this context. The results of the here presented experimental investigations shall provide a practical approach permitting researchers to overcome the main critical drawback of the friction welding technology, which is seen in the sensibility of the bond with regard to changing moisture conditions.

\section{Experimental investigations}

\subsection{Material}

High quality and almost flawless spruce boards (Picea abies) were used for the investigations. Prior to welding, the material was stored under dry climate conditions of $40{ }^{\circ} \mathrm{C}$ and $27 \%$ relative air humidity, resulting in a low equilibrium moisture content of $4 \%$. According to previous investigations a reduction of the moisture content leads to both a decrease of the scattering of the results (Stamm et al. 2011) as well as a reduction of unfavourable scale effects (Hahn et al. 2012). These restrictions correspond more to laboratory conditions than real case scenarios in which natural defects such as branches or resin chambers cannot be excluded.

\subsection{Specimen description}

Double lap joints with four different forms of surface shapes, illustrated in Fig. 2, were welded. The shape of each profile is based on a grid of $35 \mathrm{~mm}$, determined by the distance between the screw holes for the fixation of the corrugated metal plates. Besides a flat and plane surface, two shapes with an angle of $33^{\circ}$ respectively $45^{\circ}$ were 
Fig. 2 Friction welded doublelap joints with different forms of surface shapes (left) according to the defined geometric parameters (right). All dimensions in $\mathrm{mm}$

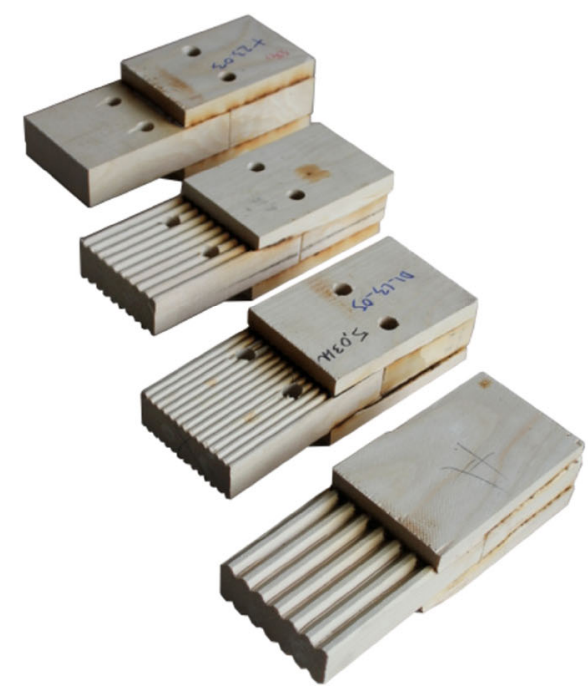

(1)

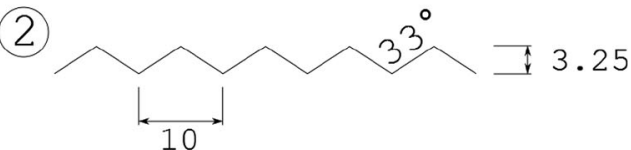

(3)

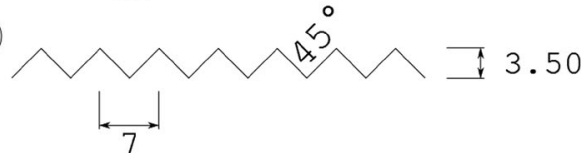

(4)

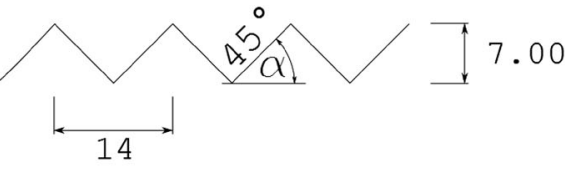

Table 1 Welding parameters used for the fabrication of double lap joints according to the different types of surface shape

\begin{tabular}{llllllll}
\hline $\begin{array}{l}\text { Surface } \\
\text { shape }\end{array}$ & $\begin{array}{l}\text { Angle } \alpha \\
\left({ }^{\circ}\right)\end{array}$ & $\begin{array}{l}\text { Welding pressure } \\
\mathrm{P}_{\mathrm{W}}(\mathrm{MPa})\end{array}$ & $\begin{array}{l}\text { Welding displacement } \\
\mathrm{d}_{\mathrm{W}}(\mathrm{mm})\end{array}$ & $\begin{array}{l}\text { Welding } \\
\text { frequency } \mathrm{f}(\mathrm{Hz})\end{array}$ & $\begin{array}{l}\text { Amplitude a } \\
(\mathrm{mm})\end{array}$ & $\begin{array}{l}\text { Cooling pressure } \\
\mathrm{P}_{\mathrm{C}}(\mathrm{MPa})\end{array}$ & $\begin{array}{l}\text { Cooling time } \\
\mathrm{t}_{\mathrm{C}}(\mathrm{s})\end{array}$ \\
\hline 01 & 0 & 1.5 & 2.00 & 130 & & 2.5 & 2.00 \\
02 & 33 & 1.6 & 2.50 & & & 2.13 & 30 \\
03 & 45 & 2.0 & 2.75 & & 2.50 & 30 \\
04 & 45 & 2.0 & 2.75 & & & 30 \\
\hline
\end{tabular}

defined. For the latter, two different sizes with relatively small peaks of $3.5 \mathrm{~mm}$ height and tall peaks of $7 \mathrm{~mm}$ height were distinguished. The welding machine used for the fabrication was a LZM75 prototype of the company Fischer Schweisstechnik, manufactured exclusively for the ongoing research project. All specimens were $100 \mathrm{~mm}$ wide and had a total length of $250 \mathrm{~mm}$ including an overlap length of $50 \mathrm{~mm}$. In a two-step process the outer layers were welded one after the other on the middle layer using a linear vibration movement. The welding parameters had to be adjusted for each surface shape and are listed in Table 1. The cross-sections of the final bond after welding are exemplarily given in Fig. 3.

\subsection{Strength tests and long-term stability}

Ten samples of each shape were tested after 1 week of storage under the above mentioned climate conditions. Pull-out tests were carried out in a displacement-controlled hydraulic testing device. Load was increased until failure level $F_{\text {ult }}$ with a displacement rate of $1 \mathrm{~mm} / \mathrm{min}$. Another set of 30 samples of each shape was stored under weekly changing climate conditions for 12 weeks. Besides the initial hot and dry settings, cold and humid conditions, namely $10{ }^{\circ} \mathrm{C}$ and $95 \%$ relative air humidity were set
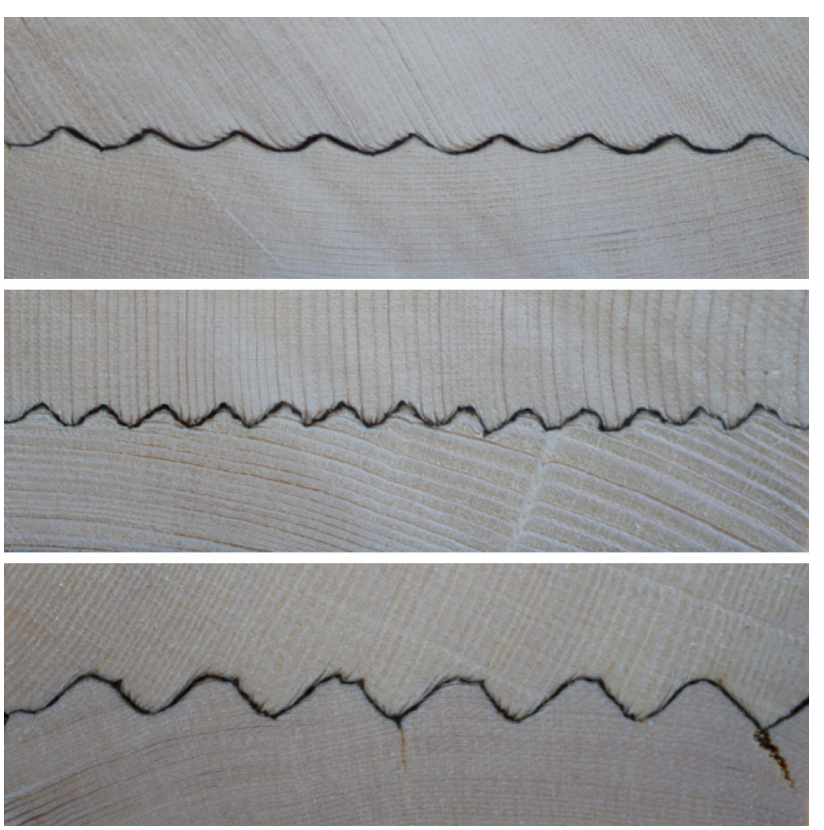

Fig. 3 Cross-section of the welded interface for three different surface shapes, from top to bottom, 02, 03 and 04

according to EN 14080 (1995), resulting in an equilibrium moisture content of $21 \%$. At the end of each cycle the samples were checked for visually detectable cracks and 


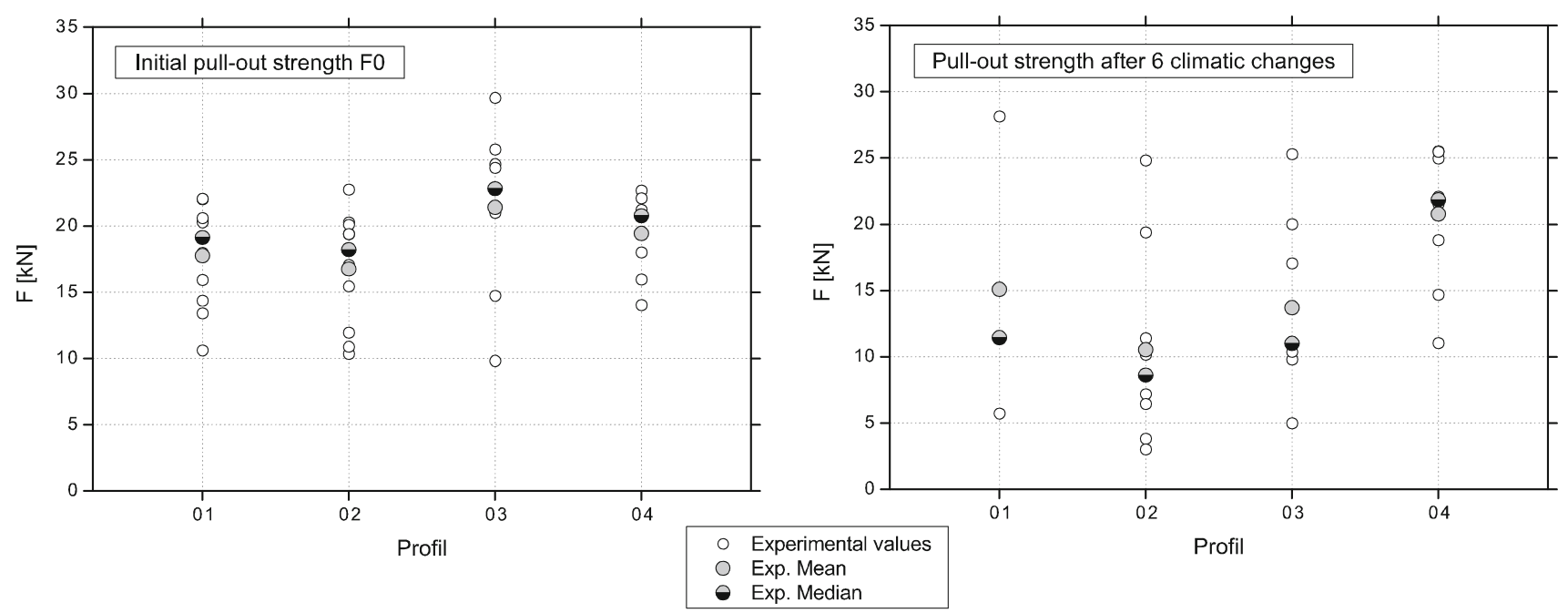

Fig. 4 Initial and residual pull-out strength of friction welded double-lap joints using different surface shapes according to Fig. 2

delamination in the weldline. The number of remaining intact samples was recorded over the whole period. The pull-out strength of the remaining samples was tested again after 12 weeks. Both, the initial pull-out strength $F_{0}$ as well as the remaining pull-out strength after 12 weeks $F_{6}$ are given in Fig. 4 as well as Table 2.

\section{Results and discussion}

Failure of the samples occurred within the welded interface in a sudden and brittle manner. Visual evaluations of the interface after testing showed no defective welding at the open interface and no test specimen had to be rejected. For some individual samples with a surface shape 03 and 04 wood particles from the opposite component remained bonded to the interface in small amounts. For all results of the initial strength $\mathrm{F}_{0}$ the scattering altered between 15 and $30 \%$. The reference value of $17.78 \mathrm{kN}$ for initially tested samples with a flat surface is in line with previous results from investigations on friction welded double lap joints

Table 2 Experimental results of pull-out tests carried out on friction welded double lap joints with different surface shapes before (F0) and after 6 climatic cycles (F6)

\begin{tabular}{|c|c|c|c|c|c|c|c|}
\hline \multirow[t]{2}{*}{$\begin{array}{l}\text { Surface } \\
\text { shape }\end{array}$} & \multicolumn{3}{|c|}{$\begin{array}{l}\text { F-Initial pull-out } \\
\text { strength }\end{array}$} & \multicolumn{4}{|c|}{ F6-After 6 climatic cycles } \\
\hline & $\mathrm{N}$ & $\begin{array}{l}\text { Mean } \\
(\mathrm{kN})\end{array}$ & $\begin{array}{l}\mathrm{SD} \\
(\mathrm{kN})\end{array}$ & $\mathrm{N}$ & $\begin{array}{l}\text { Mean } \\
(\mathrm{kN})\end{array}$ & $\begin{array}{l}\text { F6/F0 } \\
(\%)\end{array}$ & $\begin{array}{l}\mathrm{SD} \\
(\mathrm{kN})\end{array}$ \\
\hline 01 & 10 & 17.78 & 3.98 & 3 & 15.13 & 85 & 11.65 \\
\hline 02 & 10 & 16.78 & 4.39 & 9 & 10.54 & 63 & 7.22 \\
\hline 03 & 10 & 21.42 & 6.38 & 8 & 13.69 & 64 & 6.57 \\
\hline 04 & 10 & 19.44 & 3.11 & 10 & 20.78 & 107 & 4.75 \\
\hline
\end{tabular}

The column $\mathrm{N}$ represents the number of tested samples with a similar geometry (Hahn et al. 2012). The initial average strength for surface shape 02 was slightly lower than for flat surfaces, while for surface shape 03 and 04 the average was slightly increased.

The sample counts illustrated in Fig. 5 show that the number of unbroken samples welded with a flat surface shape 01 decreased rapidly during the investigations in weekly changing climate conditions. The internal stresses originating from the swelling and shrinking deformations during the tests led to remarkable cracks at the interface. After 12 weeks of climate variations, only three samples (corresponding to $10 \%$ ) with a flat surface shape 01 remained intact yielding a mean pull-out strength of $15.13 \mathrm{kN}$. A decrease in mechanic resistance could also be observed for the samples with profile shape 02 and 03 for which the average after the climatic tests corresponds to $65 \%$, respectively $64 \%$, of the initial load capacity. Nevertheless, the crack propagation after the climatic variations was reduced; around $72 \%$ of the samples from profile shape 02 and $90 \%$ of the samples from shape 03 remained intact at the end of the cycles. Best results were obtained for samples with surface shape 04, where all specimens remained intact over the whole period of testing. Additionally the mechanical resistance could be retained at the same level that was estimated prior to the climatic tests. Scattering of the mechanical resistance increased significantly for all shapes (48-77\%) except for shape 04 $(23 \%)$.

The average for the residual load capacity of the three remaining samples with a flat surface 01 is highly influenced by one sample that reached a very high value of $28.14 \mathrm{kN}$. This value has to be considered as an extreme exception since $90 \%$ of the samples with the same configuration failed without loading during the climatic tests. Taking into account only the two remaining samples 
Fig. 5 Results of the sample counts carried out after each weekly changing climatic cycle for different profile shapes and equilibrium moisture content

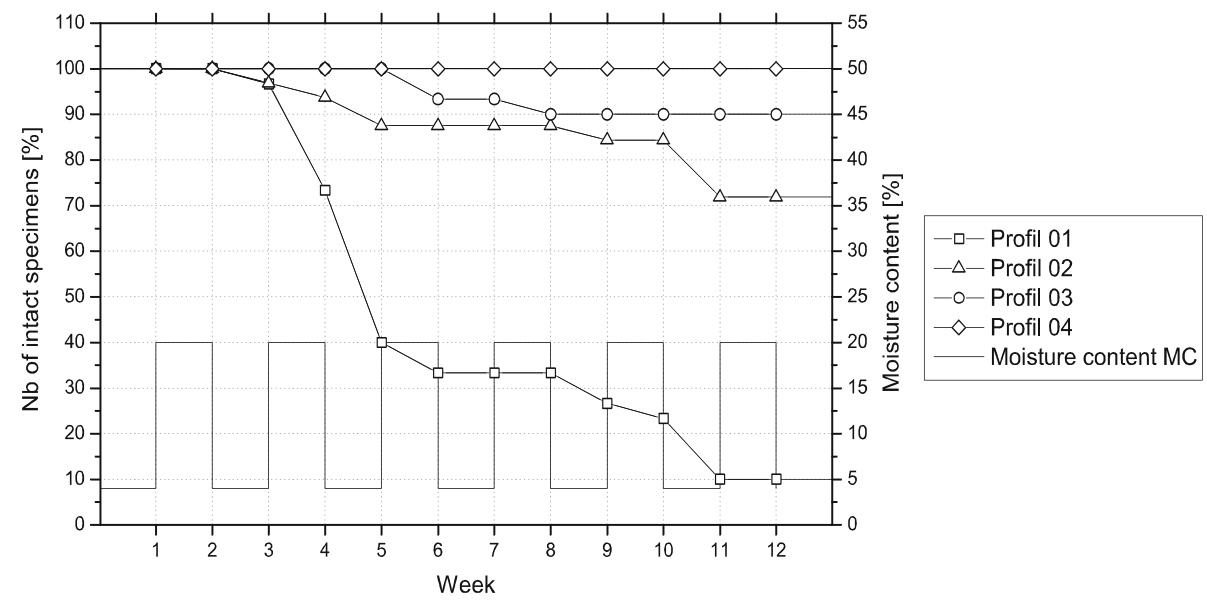

without the extreme value a low average of $8.59 \mathrm{kN}$ was obtained.

The incidence that the improvements were less significant for samples with a small shape angle $\alpha$ and small height of the peaks might be due to the fact that the shape underwent a certain flattening during the friction welding process. As a result of the compression deformations and thermo-chemical decomposition of the wood cells, the initial shape of the peaks is smoothed, as it can be seen in Fig. 3. Consequently the effect of the shaping is reduced since the keying of the elements is less straight and firm. This might explain why in previous investigations on small specimens with relatively small grooves (Omrani et al. 2009) no significant improvements of the mechanical resistance were observed.

\section{Conclusion}

In order to improve the mechanical behaviour of friction welded timber bonds, the influence of a modification of the shape of the welded interface was investigated experimentally. In addition to a plane and smooth surface configuration, three different triangular geometries were applied to the surface of the friction welded double lap joints prior to welding. The welded samples were exposed to weekly changing moisture conditions and mechanical tests were carried out both before and after 12 weeks of climate variations. The results showed that:

- Flat and plane interfaces are very sensible to swelling and shrinking deformations that result from changing moisture conditions and lead to irreversible crack formation. Load bearing capacity disappears almost completely after some cycles with changing climate conditions.

- The initial joint strength can be improved by welding shaped samples with an inclination of $45^{\circ}$. The welding

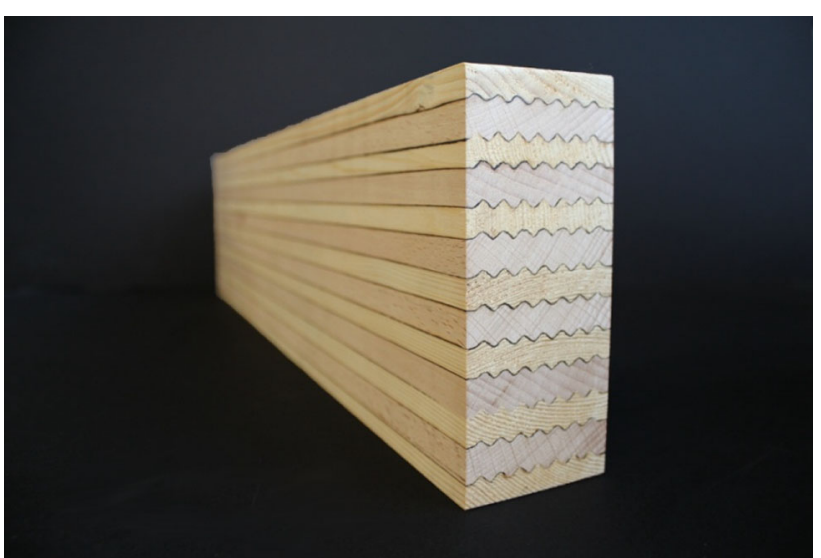

Fig. 6 Small scale prototype of a friction welded laminated beam section composed of spruce and beech wood

parameters have to be adapted to the profile and especially to the inclination of the shape angle.

- Interlocking of the welded interfaces by means of profiled surface shapes results in significant improvement of the stability of the joint under changing moisture conditions. The inclination as well as the depth of the grooves have an influence on the moisture behaviour of the joint.

The results show that under certain conditions the strength of the welded connection can be maintained even under significant variations in moisture content. Thus, a promising approach is found to overcome the main drawback of the technology with respect to industrial application. An example of such an application in timber construction is seen in automated prefabrication processes for laminated timber beams. The required technical extension of the process can be realised by a serial arrangement of several units that are identical to the welding device used for these investigations. Since the friction process time of around $6 \mathrm{~s}$ is very short, the energy 
consumption of such a device per $\mathrm{m}^{2}$ bond is considered as being relatively low. In addition, no additional costs for the glue have to be considered.

In theory, the modifications presented herein can directly be applied to friction welded beam sections, such as it is illustrated in form of a small scale prototype in Fig. 6. Ongoing research at the IBOIS also focusses on the fabrication of cross-welded board layers (Hahn et al. 2014b), where much higher internal stresses are expected. Therefore, additional measures, such as stress-grooves or profile optimisation, have to be investigated hereinafter.

Acknowledgments The present research work was funded by the Swiss National Foundation and is part of the project "SNF-Sinergia Project no. CRSI22 127467/1".

\section{References}

EN 14080 (1995) Timber structures-glued laminated timberrequirements

Gfeller G, Zanetti M, Properzi M, Pizzi A, Pichelin F, Lehmann M, Delmotte L (2003) Wood bonding by vibrational welding. J Adhes Sci Technol 17:1573-1589

Gliniorz KU, Natterer J (2000) Holzschweißen-Innovative Verbindungstechnologien im Holzbau (Wood welding-Innovative connection technologies in timber construction) (In German).
In: Proceedings, Symposium der Ligna Plus/Weltmesse für die Forst-und Holzwirtschaft in Hannover, pp 9-18

Hahn B, Vallée T, Stamm B, Weinand Y (2012) Experimental investigations and probabilistic strength prediction of linear welded double lap joints composed of timber. Int J Adhes Adhes 39:42-48

Hahn B, Stamm B, Weinand Y (2014a) Linear friction welding of spruce boards: experimental investigations on scale effects due to humidity evaporation. Wood Sci Technol 48:855-871

Hahn B, Vallée T, Stamm B, Weinand Y (2014b) Moment resisting connections composed of friction-welded spruce boards: experimental investigations and numerical strength prediction. Eur $\mathrm{J}$ Wood Prod 72:229-241

Omrani P, Mansouri HR, Pizzi A (2009) Linear welding of grooved wood surfaces. Eur J Wood Prod 67:479-481

Pizzi A, Properzi M, Leban JM, Zanetti M, Pichelin F (2003) Mechanically-induced wood welding. Maderas Ciencia y tecnologia 5:101-106

Stamm B, Natterer J, Navi P (2005) Joining of wood layers by friction welding. J Adhes Sci Technol 19:1129-1139

Stamm B, Weinand Y, Hahn B, Rossmair G (2011) Influence of the moisture content on the shear strength of welded wood-to-wood connections. In: COST Action FP0904 Mechano-chemical transformations of wood during THM processing, 16-18 February 2011 , Biel $(\mathrm{CH})$

Sutthoff B, Franz U, Hentschel H, Schaaf A (1996) Verfahren zum reibschweißartigen Fügen und Verbinden von Holz (Method for a friction-welding inspired joining and fastening of wood), German patent DE 19620273 C 2 